\title{
The Use of i-Think Map and Questioning to Promote Higher-Order Thinking Skills in Mathematics
}

\author{
Siti Ruzila Hassan, Roslinda Rosli, Effandi Zakaria \\ Faculty of Education, The National University of Malaysia, Bangi, Malaysia \\ Email: roslinda@ukm.edu.my
}

Received 8 April 2016; accepted 24 May 2016; published 27 May 2016

Copyright $@ 2016$ by authors and Scientific Research Publishing Inc.

This work is licensed under the Creative Commons Attribution International License (CC BY).

http://creativecommons.org/licenses/by/4.0/

$$
\text { (c) (i) Open Access }
$$

\section{Abstract}

The 21st century education demands transformation in teaching in order to produce students who are able to meet the challenges by applying higher-order thinking skills. Malaysia is taking the initiative to introduce i-Think program since 2012 to support the aspiration. This article provides guidelines and proposes the use of thinking map in mathematics, focusing on the topic of polygon under geometry. The recommendations of appropriate questioning for teachers to stimulate higher-order thinking skills of students are also discussed.

\section{Keywords}

i-Think, Thinking Map, Higher-Order Thinking Skills, Questioning

\section{Introduction}

The strength and progress of a country depend on the level of knowledge and skills of the people. Therefore, the education system plays an important role in delivering the knowledge and skills to the students. Consequently, Malaysia continues to experience a transformation in education arena from time to time.

Education Development Plan of Malaysia (PPPM) 2013-2025 has outlined six main features needed by each student in order to meet the challenges at the global level, in line with the philosophy of national education, namely:

- Knowledge

- Thinking skills

- Leadership skills

- Bilingual skills 
- Ethics and spirituality

- National identity

One of the aspects which has been highlighted in the PPPM is thinking skills. For the success of this intention, higher-order thinking skills are given specific emphasis so that the current education system is capable of producing students who are competitive in facing the challenges in the 21 st century. Since Malaysia has set a target to achieve the ranking of $1 / 3$ of the top in the international tests of TIMSS and PISA, initiatives have been taken to promote higher-order thinking skills among the students. The i-Think map is chosen as a visual tool in helping the teachers to achieve the target. It is expected that the tool will directly help the teachers to deliver knowledge and guide the students to organize their concept or ideas in a systematic manner. Hence, it will also boost the students' higher-order thinking skills indirectly.

\section{Higher-Order Thinking Skills}

Higher-order thinking skills, in short, HOTs, are one of the main components in creative and critical thinking skills and it is the highest level in a hierarchy of cognitive process. HOTs occur when one gets new information, stores, organizes and associates it with the existing knowledge and then forward the information to achieve a specific object or the solution of a problem. HOTs involve cognitive skills i.e. skills to analyze, synthesize, evaluate and produce a new idea. It requires more than memorizing facts (rote memory) like a robot which is programmed but cannot think by itself. HOTs lead people to use the facts and make connections between other facts or concepts, manage to categorize, manipulate them and apply them for new solution for other situations (Thomas \& Thorne, 2014). In order to stimulate students' thinking, questioning could be used as a tool to promote the students to think out of their normal thinking box. Students who are engaged in questioning process will be able to clarify their thinking, come out with new ideas and enhance problem solving skills (Wang et al., 2015).

As for the Malaysian Curriculum Development Division, HOTs is defined as "the ability to apply knowledge, skills and values in making of reasoning and reflection for problem solving, decision making, innovative and able to create something" (Kementerian Pendidikan Malaysia, 2013). The items of HOTs shall assess cognitive skills by analyzing, evaluating and creating. The items can also be cognitive skills in new situations to resolve daily life problems. Therefore, HOTs items test the ability of students to apply knowledge, skills and values in making of reasoning and reflection for problem solving, decision making, innovative and able to create something. Students are able to apply and use knowledge in new situations, analyze and deliver ideas to components, to understand the relationship between components and can make judgments and decisions based on specific criteria. In addition, students can also create or think of new ideas and new ways by using the information.

Bloom et al. (1956) had created an outlined taxonomy as the basis for the objective of teaching. The taxonomy is a classification system comprised of six level of thinking development and has been the main reference to educators since so long until it was revised (Anderson \& Krathwohl, 2001). The revised taxonomy was formed by providing some improvement against the original taxonomy involving critical, logical, creative, reflective thinking and meta-cognitive. Figure 1 shows the comparison between the two taxonomies. These higher-order thinking skills focuses on four top level in Bloom's Taxonomy which is application, analysis, synthesis, and evaluate. Therefore, the four highest level in the revised taxonomy, which are applying, analyzing, evaluating and creating are also considered referring to higher-order thinking skills.

\section{Rationales}

Based on the students' achievement over the past two decades in the international assessments such as the Program for International Students Assessment (PISA) and Trends in International Mathematics and Science Study (TIMSS), some analyses were made. The assessment takes into account a variety of cognitive skills such as application and reasoning. These assessments are also used as the benchmark and provide a direct comparison towards the quality and success in education systems of the countries that took part.

When Malaysia participated in TIMSS for the first time in 1999, the average score of Malaysian students was above the mathematics and science international score. However, the participation in 2007 recorded that the performance of Malaysian students was below the international average for mathematics and science, causing a reduction in the ranking among countries. To be exact, $18 \%$ and $20 \%$ of Malaysian students failed to reach the minimum level of skill in mathematics and science in 2007, an increment of two to four times from $7 \%$ and $5 \%$ 


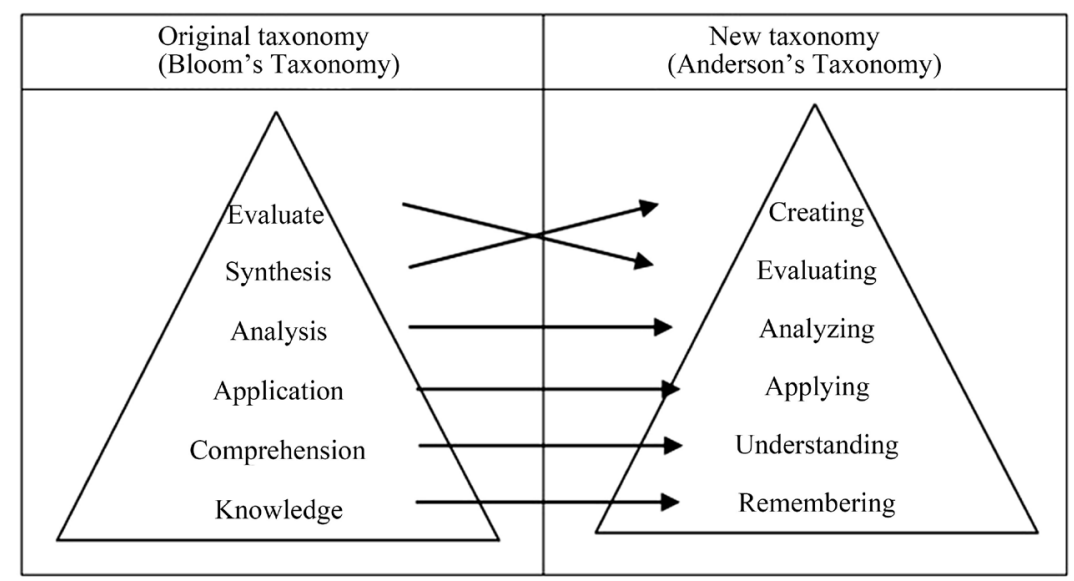

Figure 1. Bloom's taxonomy (left) and the revised version by Anderson and Krathwohl (right). (Source: Schultz, 2005).

respectively in 2003. The report of TIMSS 2011 also revealed the reduction of Malaysia's position in mathematics, namely at position 16 (year 1999), 10 (year 2003), 20 (year 2007), and 26 (year 2011). Similarly, the drop in average scores were 519 (year 1999), 508 (year 2003), 474 (year 2007) to 440 (year 2011).

The results of the PISA 2009 for Malaysia's first participation were also discouraging because its position was in the lowest third cluster among 74 participant countries. Countries that are considered to be less developed than Malaysia such as Thailand and Vietnam were placed in higher rank. This achievement also placed Malaysia under international and OECD (Organization of Economic Cooperation and Development) average achievements (OECD, 2014). PISA which was introduced by OECD is a valid platform for the country members to evaluate their education accomplishment in certain areas. As for mathematics achievement, Malaysia was ranked 57th by attaining 404 points, below the average of 458 points at the OECD level. In general, almost $60 \%$ of students aged 15 years who joined PISA failed to reach the minimum level of skills in mathematics, while $44 \%$ and $43 \%$ did not reach the minimum skills in reading and in science respectively. Since the competency of the students' skills in these areas could not reach the international standard, the students should be exposed to the format of PISA items and the needed skills for better achievement in the following tests.

The form of the questions tested in PISA gives more focus on problem solving that requires higher-order thinking skills, such as analyzing, evaluating or synthesizing and not merely remembering or understanding. Thus, it gives an indication that Malaysian education system is still weak in the aspects evaluated. Therefore, it is a requirement for the students to be equipped with the skills. Findings from international assessments (PISA and TIMSS) have raised the concerns since the students' competency was very low especially on problem solving questions that require higher-order thinking skills. Hence, the i-Think program was introduced to stimulate students' critical and creative thinking and promote higher-order thinking skills.

The National Education Blueprint 2013-2025 plan has set a target that Malaysia needs to achieve an average score of 500 in TIMSS by 2015 and 2025, so that it will be ranked at $1 / 3$ of the top in the TIMSS and PISA. Therefore, higher-order thinking skills should be applied in Malaysian education system generally and mathematics education specifically because the students need to have the capability of reasoning and apply knowledge creatively in a non-routine manner.

By the year 2016, the percentage of higher-order thinking questions will be added up to cover $80 \%$ of the total in Primary School Achievement Test (UPSR) for year 6 students, $80 \%$ of the questions in Form 3 assessment (PT3) for form 3 students, $75 \%$ of the total questions for core subjects and $50 \%$ for elective subjects in SPM examination for form 5 students. This change will evade the teachers from predicting the questions that will be asked in prior while the students are trained to think critically and apply the knowledge learned in various contexts. On the other hand, school-based assessments will also focus on higher-order thinking skills.

The former Malaysian education system based on examination oriented has led the teachers to apply the approach of memorizing in teaching the students. Teaching is fully prepared for the examination. Therefore, students are able to obtain full marks for the questions that require the memorization of facts. Hence, HOTs is introduced to change such practices, in line with the government's aspiration to make Malaysia a developed coun- 
try by the 21 st century. In addition, other purposes of HOTs being introduced are to:

1) increase the level of awareness of knowledge

2) justify the solution and discovery (more analysis, evaluate and create)

3) scientific investigation

4) learn the concept of math more effectively using HOTs

5) improve the ability of students in investigating and exploring mathematical ideas

\section{Visual Tools}

Research by Githua \& Nyabwa (2008) showed that advance organizers improved students' achievements which made a contribution to know-how in its area. Students who were taught mathematics through advance organizers performed significantly much better than those who had been taught through the traditional teaching approaches. As for local, research by Zulnaidi \& Zakaria (2010) indicated that using information mapping strategy may impact students' conceptual knowledge. There were also interactions between mathematics conceptual understanding and mathematics achievement. Similarly, Zaini, Mokhtar, \& Nawawi (2010) found that the use of graphic organizers had given effects on the improvement of students' comprehension, performance and motivation in learning.

Another research by Olarewaju \& Awofala (2011) revealed that mapping is an efficient strategy for helping students to master mathematical concepts. The particular strategy can also be able to strengthen students' mastery allied with information at the higher-order thinking. The comprehensive research made by Tripto, Assaraf, \& Amit (2013) towards 11th grade students found that the strength of the concept map is within the ability to describe the thinking level of analyzing and synthesizing. From the findings listed, suggestions can be made to include concept mapping in teaching strategies in secondary schools.

Realizing that the visual tools, namely mind maps, conceptual diagrams, visual metaphors, advance organizer, concept mapping and many other similar graphic organizers proven to give impact on the students' understanding and achievements, a visual tool named i-Think is considered to be relevant as a tool to promote students' thinking. I-think as thinking maps are non-linguistic representations. So are graphic organizers. However, thinking maps are different from graphic organizers as they are visual representations of thinking. Unlike graphic organizers which promote activities, thinking maps promote strategic thinking to help students to see which thinking skills are appropriate to be used to solve problems.

\section{5. i-Think Thinking Map}

Thinking map (i-Think) is a program to enhance and promote the skills of thinking among students to produce a generation that is able to innovate as shown in Figure 2. The i-Think means "innovative thinking" which pupils are provided with the skills of thinking. The purpose of introducing i-Think is to produce human capital that has a critical and creative thinking, innovative and competitive in future. Thus, the Ministry of Education of Malaysia has been working with National Innovation Agency (AIM) to introduce i-Think program. A total of six primary schools and four secondary schools have been selected as the pioneer to implement this program starting in 2012.

Eight maps in i-Think Map is listed in Figure 3, consist of Circles Map, Bubble Map, Double Bubble Map, Tree Map, Brace Map, Flow Map, Multi-Flow Map and Bridge Map. Each Map has its own thinking process. According to Hyerle and Yeager (2007) who developed i-Think Map project, the process of thinking and reasoning becomes a culture when the teachers and students practice the thinking skills and reasoning during teaching and learning. With the availability of the tools to think, teachers and students are able to perform these skills. Thinking will become a practice when teachers and students in the classroom solve higher level inquiry-based questions through student-centered activities by using the thinking tools. The i-Think map is one of the thinking tools presented in eight forms of visual thinking map which can be easily applied and understood across mathematics curriculum.

\section{The Use of Thinking Maps}

Polygon is one of the topics that are taught to Form One students in secondary schools in Malaysia. There are four learning objectives listed, which are: 


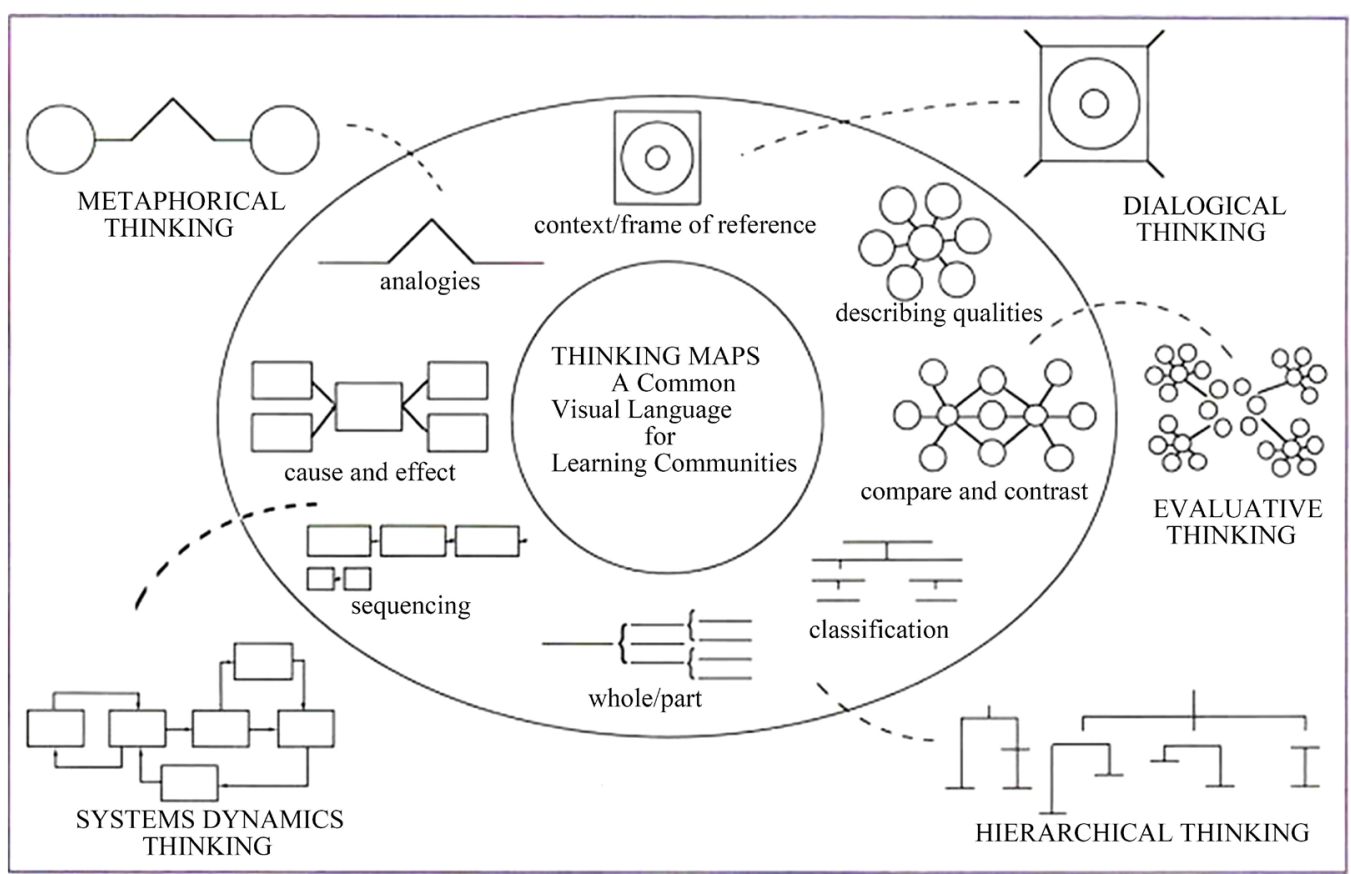

Figure 2. Thinking maps. Source: Hyerle (1995). Thinking maps: seeing is understanding.



Figure 3. Thinking maps. Source: Hyerle \& Yeager (2007). Thinking maps: a language for learning. 
1) to understand the concept of polygons

2) to understand the concept of symmetry

3) to identify and use the geometrical characteristics of triangular to solve problems

4) to identify and use the geometrical characteristics of quadrilateral to solve the problems

Each objective has a number of prescribed learning outcomes. For the purpose of this writing, focus is given to the third objective, which is to identify and use the geometrical characteristics of triangular to solve problems. At the end of the lesson, students will be able to specify the geometrical characteristics for different types of triangles. Students are expected to have prior knowledge on the terminology of sides, vertices and angles. Students are also able to define and draw the line of symmetry of a given triangle and able to draw a triangle by using the protractor and ruler.

The teaching steps:

1) First Activity (Individual)

The first step starts when every student is instructed to fill in the Bubble Maps as shown in Figure 4. In this writing, a right-angled triangle and an obtuse-angled triangle are chosen for examples. A series of questions are asked by teachers to guide the students to fill in the maps and to stimulate their thinking skills, involving the skill of applying as in Bloom's Taxonomy. The questions could be:

1) Do you remember the name of this polygon...?

2) What can you see at the characteristic of its shape, the vertex ...the angles...?

3) Look at each side of the polygon ....are all sides having the same length...?

4) Is there any axis of symmetry existed in this polygon... How many can you identified?

5) What type of angles can you find in this polygon? Can you name them?

6) Can you identify the value of any angle in this polygon?

7) Figure 5 and Figure 6 show the suggested answers that student might give. However, any other answers which are relevant are also can be accepted.

8) 2) Second Activity (Individual)

9) The second activity requires each student to fill in the Double Bubble Map for any two polygons chosen by teacher earlier on the first activity. Here, right-angled triangle and obtuse-angled triangle are chosen. The base diagram for Double Bubble Map is shown in Figure 7. This map is used to compare and contrast the characteristics of each polygon.

10)Students are asked to observe the characteristics of both triangles and then analyze their similarities and differences which involve the skill of analyzing. Less guidance is given by the teacher compared to the first activity. Suggested answers are shown in Figure 8 and again, any other answers which are relevant are also accepted.

\section{The Questioning in Enrichment Activities}

For enrichment activities, the skill needed is creating, the highest level in the revised Bloom's Taxonomy. The students are given a group-task to create the equipment for children in the playground. Equipment can be swings, see-saw, slides, climbers, gliders and others which appropriate or a combination of them. The shape of the triangle

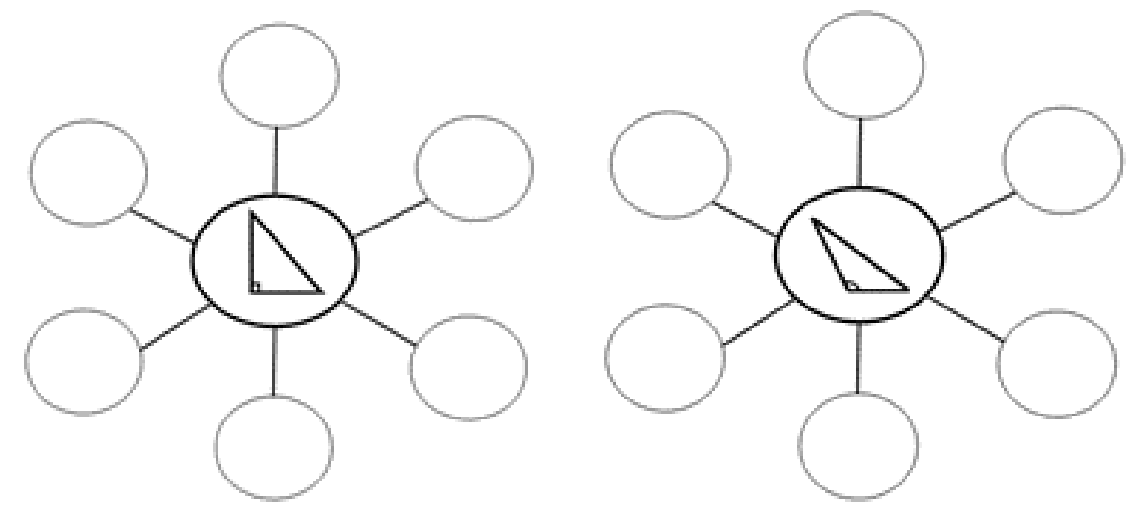

Figure 4. The base diagrams for bubble maps. 


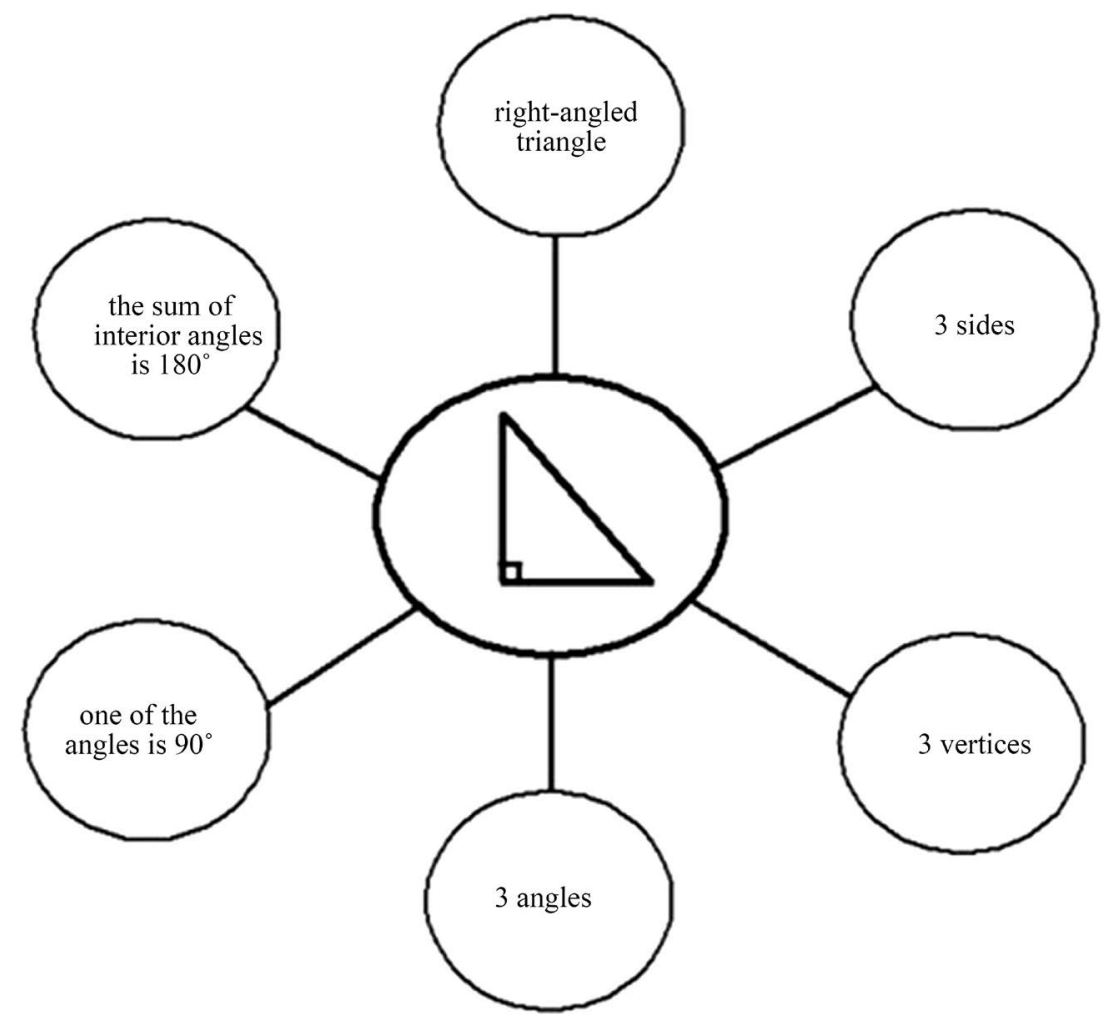

Figure 5. Suggested answers for bubble map for a right-angled triangle.

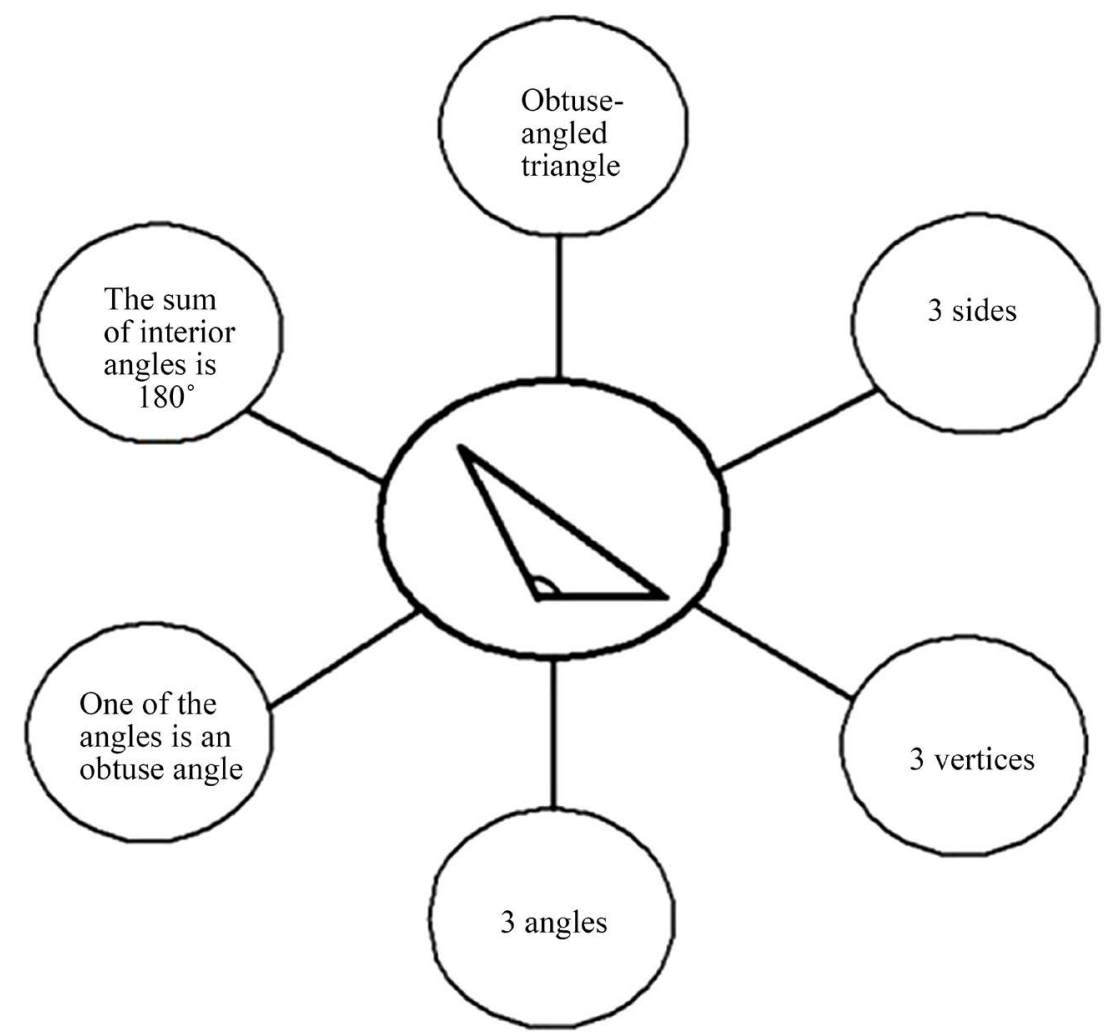

Figure 6. Suggested answers for bubble map for an obtuse-angled triangle. 


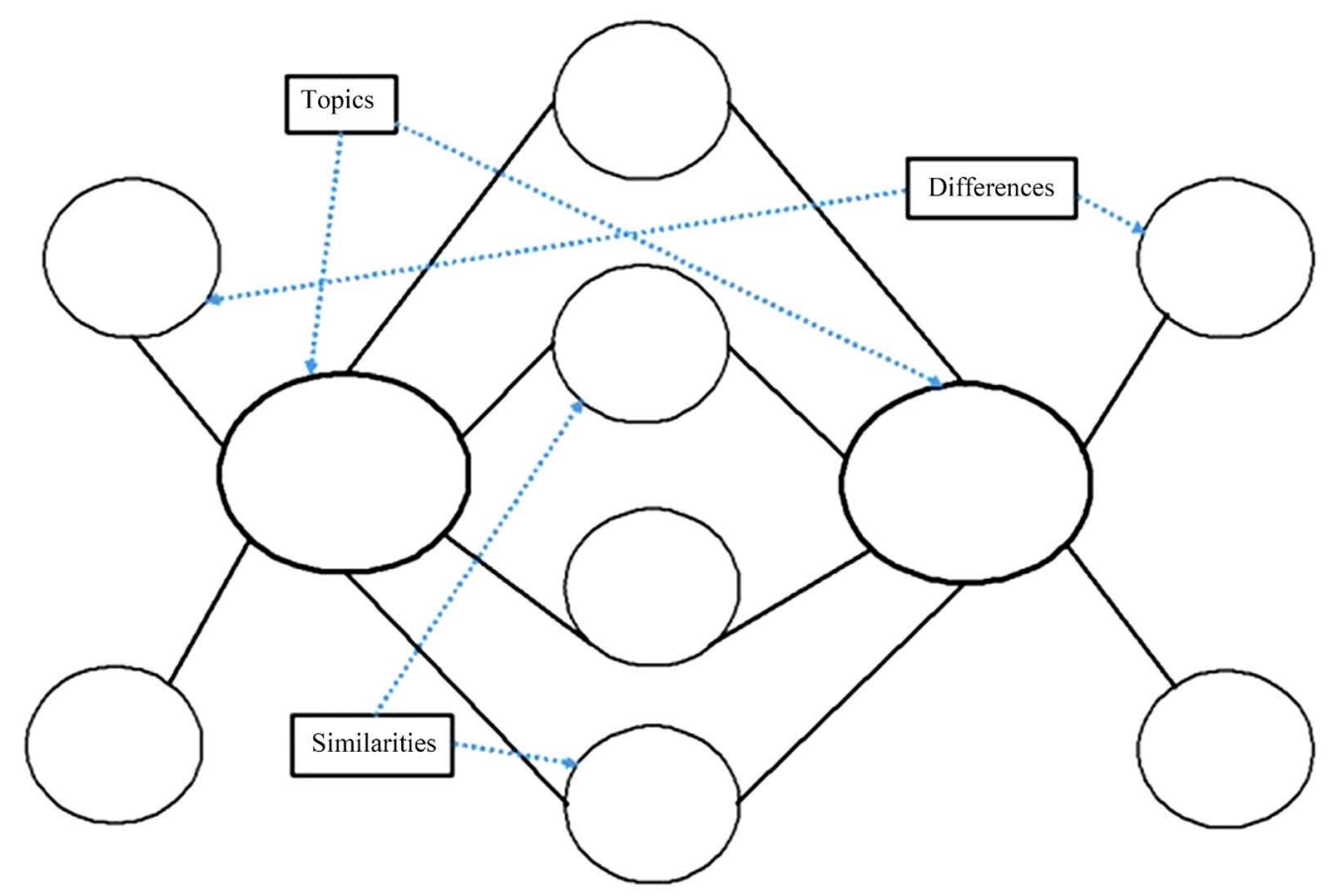

Figure 7. The base diagrams for double bubble map.

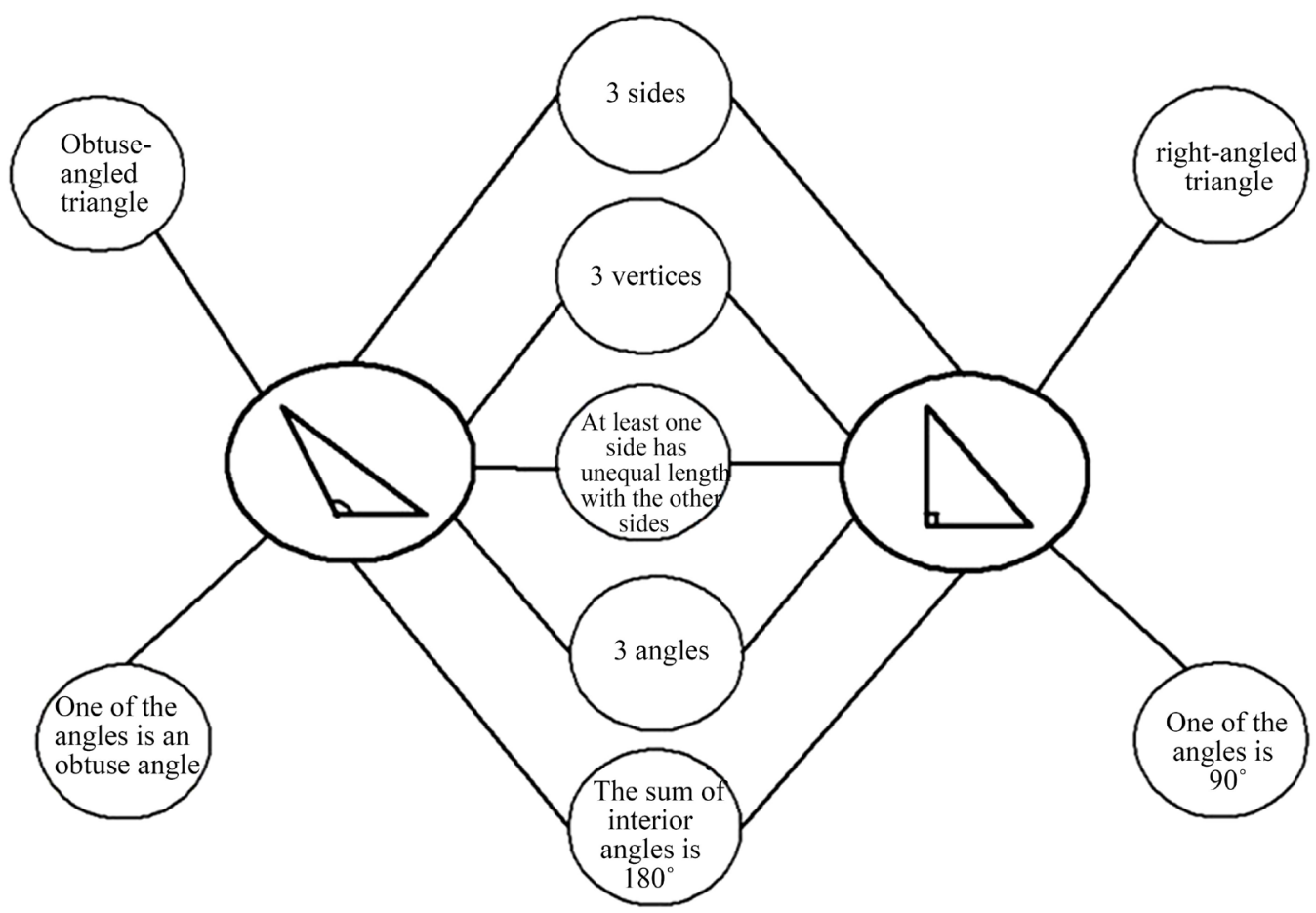

Figure 8. Suggested answers for the double bubble Map for an obtuse-angled triangle and a right-angled triangle.

is the main shape that must be used in creating the structure of equipment but other shapes may also be used as a support. Six kinds of triangles are given, which are acute, obtuse, right, equilateral, isosceles and scalene triangles as shown in Figure 9 to be used to form the equipment. Any combinations of other appropriate shapes are accepted. 


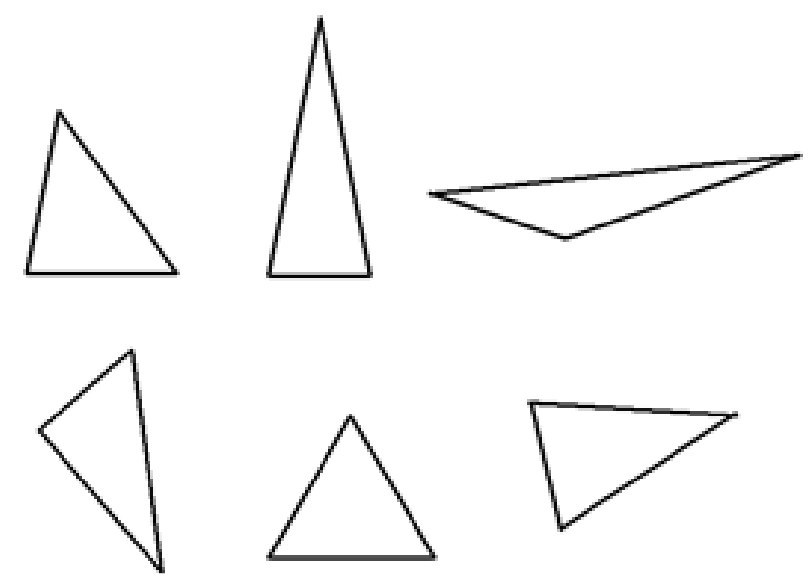

Figure 9. Six basic types of triangle as the basis for creating playground equipment.

Before deciding the types of triangles to be chosen and the equipment to be created, a series of questions can be asked to stimulate students' thinking. This is also considering as a reinforcement of the students' understanding towards the concept of triangles.

\section{A Sample Task for Enrichment Activity}

You and your friends are given the opportunity by a developer to design creative equipment for children's play-ground with certain conditions. It is compulsory for you to use triangular shapes as the main structure. There are six kind of triangles which can be chosen as shown in the attachment (Figure 9). However, you are allowed to use other shapes to support your design from the attachment. Discuss and draw the design of the equipment as creative as you can at the provided blank space.

Before the students carry out the task, a series of questions could be asked by the teacher. Here are the examples of questioning the teacher could ask to stimulate the students' thinking while creating the design:

1) What kinds of triangle/s that appropriate to be used as a main structure for the equipment you choose?

2) Why does the triangle/s being selected? Give your reasons for every selected triangle

3) Explain the main factor being considered when you choose the triangle/s

4) Suggest the value of the angle that should be used at each vertex of the triangle. Indicate why the angle value is proposed

5) Is there any improvement or new invention that you would like to apply for your design? What makes your design considered creative?

6) To convince the company, state the reasons why your design should be chosen Notes:

1) Make sure that the characteristics of the triangles you choose suits the design

2) Name every triangle you choose and label every vertex of the triangle with estimated value of angle

3) You are allowed to design more than one combination of equipment

4) Draw the design as clear as you can, preferably in $3 \mathrm{D}$

5) Please present your design to other groups

When the presentation is carried out by each group, more questioning might be voiced out either by the teacher or the audience. Therefore each member in the group has to prepare to defend their design by giving reasons and the thinking process would never end.

\section{Conclusion}

The awareness about the importance of higher-order thinking skills in society is becoming stronger. The awareness has been driven by the changes in education at the international level. These changes demand students to be equipped with the knowledge and skills so that they can deal with the problem-solving in daily life. One of the efforts taken is by introducing i-Think program to help stimulating higher-order thinking skills among students. 
Teachers play important roles in ensuring the implementation of the program to be a success. Collaboration among teachers or schools in setting up a map-bank of i-Think maps is suggested. This effort will create a collection of easy-access tool that can be reached at any time. The compilation of various applicable maps for certain mathematics topics, preferably online, is certainly a hassle-free way in sharing the resources. However, the selection of thinking maps being used in every case should be made appropriately and teachers can stimulate HOTs among students by providing challenging questions. The implementation of this program should be carried out continuously, so that the culture of thinking becomes a habit for the students at all time. It is also recommended that other researchers conduct experimental studies using i-Think maps as an intervention to identify its effectiveness in a real classroom setting.

\section{References}

Anderson, L. W., Krathwohl, D. R., \& Bloom, B. S. (2001). A Taxonomy for Learning, Teaching, and Assessing: A Revision of Bloom's Taxonomy of Educational Objectives. Boston, MA: Allyn \& Bacon.

Bloom, B. S., Engelhart, M. D., Furst, E. J., Hill, W. H., \& Krathwohl, D. R. (1956). Taxonomy of Educational Objectives: The Classification of Educational Goals by a Committee of College and University Examiners (Handbook I: Cognitive Domain). New York: Longmans Publishing.

Githua, B. N., \& Nyabwa, R. A. (2008). Effects of Advance Organiser Strategy during Instruction on Secondary School Students' Mathematics Achievement in Kenya's Nakuru District. International Journal of Science and Mathematics Education, 6, 439-457. http://dx.doi.org/10.1007/s10763-006-9037-8

Hyerle, D. (1995). Thinking Maps: Seeing Is Understanding. Educational Leadership, 53, 85-89.

Hyerle, D., \& Yeager, C. (2007). Thinking Maps: A Language for Learning. Cary, NC: Thinking Maps, Inc.

Kementerian Pendidikan Malaysia (2013). Pelan Pembangunan Pendidikan Malaysia 2013-2025. Putrajaya: Bahagian Pendidikan Guru.

Wang et al. (2015). Teacher Questioning in College English Class: A Guide to Critical Thinking. Global Journal of Human-Social Science Research, 15, 11.

OECD (2014). PISA 2012 Results in Focus: What 15-Year-Olds Know and What They Can Do with What They Know. http://www.oecd.org/pisa/keyfindings/pisa-2012-results-overview.pdf

Olarewaju, A., \& Awofala, A. (2011). Effect of Concept Mapping Strategy on Students' Achievement in Junior Secondary School. Journal of Mathematical Trends and Technology, 2, 11-16.

Schultz, L. (2005). Bloom's Taxonomy. Lynn Schultz: Old Dominion University. Accessed on 6 September 2015.

Thomas, A., \& Thorne, G. (2014). How to Increase Higher Order Thinking. Accessed on 5 March 2016. http://www.readingrockets.org/article/34655

Tripto, J., Assaraf, O. B., \& Amit, M. (2013). Mapping What They Know : Concept Maps as an Effective Tool for Assessing Students' Systems Thinking. American Journal of Operations Research, 2013, 245-258. http://doi.org/10.4236/ajor.2013.31A022

Zaini, S. H., Mokhtar, S. Z., \& Nawawi, M. (2010). The Effect of Graphic Organizer on Students' Learning in School Types of Graphic Organizer. Malaysian Journal of Educational Technology, 10, 17-23.

Zulnaidi, H., \& Zakaria, E. (2010). The Effect of Information Mapping Strategy on Mathematics Conceptual Knowledge of Junior High School Students. US-China Education Review, 7, 26-31.

http://www.eric.ed.gov/ERICWebPortal/recordDetail?accno=ED511227 